\title{
AUTONOMIA, HETERONOMIA: OBSERVAÇÃO SOBRE A RELAÇÃO ENTRE CORPO E ESTRUTURA NA OBRA DE JACQUES LACAN ${ }^{1}$
}

\author{
Léa Silveira Sales ${ }^{2}$
}

Resumo:Os anos de 1954 e 1955 correspondem a um momento da obra de Jacques Lacan que pode ser apontado como o auge do recurso mais direto à estrutura que, conformada pelos significantes, responde pela total determinação do sujeito. Neles, o "efeito de sujeito", a partir de sua própria definição, chega a dispensar explicitamente associações com o ser humano, em termos do que essa expressão pudesse indicar como suporte vital, qualquer que fosse. Com a construção do grafo do desejo (1957), o problema passa a receber uma nova configuração. Assiste-se, então, a uma insistente recuperação do papel do corpo na constituição do desejo a partir do modo como é pensada a relação deste com a necessidade e com a demanda. Este artigo aborda os termos dessa reinserção e procura indicar em que sentido ela começa a circunscrever um dos vetores da ultrapassagem da racionalidade estruturalista.

Palavras-chave: Psicanálise. Estruturalismo. Corpo.

Durante longos anos fiz vocês se dobrarem à noção, que deve permanecer primeira e prevalente, do que constitui o significante como tal, ou seja, as estruturas de oposição cuja emergência modifica profundamente o mundo bumano. Só que esses significantes são, em sua individualidade, modelados pelo homem, $e$ provavelmente ainda mais com suas mãos do que com sua alma.

Lacan, 1986/1988.

Os anos de 1954 e 1955, especialmente representados pelos seminários sobre o eu (Lacan, 1978) e sobre $A$ carta roubada (Lacan, 1957/1966a), correspondem a um momento da obra de Jacques Lacan que pode ser apontado como o auge do

1 Esse artigo deriva de uma pesquisa de doutorado financiada pela CAPES. Sob forma reduzida, foi apresentado no III Congresso de Pós-Graduação da Universidade Federal de São Carlos.

2 Doutoranda em Filosofia, Universidade Federal de São Carlos. E-mail: lea_silveira@uol.com.br

PSICOL. USP, São Paulo, jul./set. 2007, 18(3), 75-89 
recurso mais direto ao plano estrutural que, conformado pelos significantes, responde pela total determinação do sujeito. Neles, o "efeito de sujeito", a partir de sua própria definição, chega a dispensar explicitamente associações com o ser humano, em termos do que essa expressão pudesse indicar como um suporte vital, qualquer que fosse. Lacan diz, por exemplo, que,"em si mesmo, o jogo do símbolo representa e organi$z a$, independentemente das particularidades de seu suporte humano, este algo que se chama um sujeito" (Lacan, 1978, p. 227, itálicos nossos). O sujeito aparece como produto de um funcionamento simbólico, algo que este gera independentemente da vida - "não é preciso... que seja um sujeito animado" (Lacan, 1978, p. 227, 280) - ou de qualquer outra coisa, e nada nas descrições que encontramos no período mencionado o atrela necessariamente a um corpo de ser humano. Essa configuração, que, como mostraremos mais adiante, se modifica intensamente a partir do Seminário 5, pode ser vista como o primeiro resultado do encontro da estrutura com a decisão, já antiga, de não definir a subjetividade por recurso a alguma substância ou entidade interna: sob o viés externalista garantido pela noção de inconsciente, desde que relida mediante diretrizes estruturalistas - sobretudo as que podemos encontrar na obra de Lévi-Strauss -, abole-se da concepção de sujeito o suporte vital.

Depois disso, no Seminário 3, estudando o mecanismo da psicose (Lacan, 1981), e no 4, tratando do Édipo do pequeno Hans e da fobia (Lacan, 1995), nada se colocava de modo a que o ponto pudesse ser revisto. Já no 5 e no 6 , as coisas se passam de outra forma. Aí, as reiteradas explanações do grafo do desejo simplesmente não deixam nenhuma margem para que se exclua o corpo da definição de sujeito do inconsciente. Ou seja, não há mais como pensar que o sujeito não seja algo necessariamente relacionado a, ou mesmo implicado por, um corpo. Evidentemente, a questão não está em retornar a alguma idéia de substância, muito menos a um biologismo. O motivo desse deslocamento reside, antes, no seguinte: após um movimento no qual o sujeito é mais rigorosamente trabalhado como a pura negatividade do desejo sob a incidência do significante, torna-se possível tratar de sua relação - desde que negativa - com algo aquém da fala, uma vez que esse algo aquém da fala, sendo sempre presença negativa, não está mais sob a mira do substancialismo. Para tanto, convém retomar de modo mais crucial um certo vínculo negativo com a biologia,já muito elaborado, principalmente nos anos 30. Lacan ponderava, no Seminário 11, que "com o termo sujeito... não designamos o substrato vivo que é necessário ao fenômeno subjetivo" (Lacan, 1973, p. 142). Nisso, diz-se, com efeito, que o sujeito não é esse substrato vivo, mas, ao mesmo tempo, diz-se também que precisa dele, se bem que, mais uma vez, seja da ordem da negação o laço entre os dois. Quer dizer, se o organismo só se apresenta para ser excluído ou superado (tal como a relação com a prematuração do nascimento traba- 
Ihada a partir de Louis Bolk ${ }^{3}$ ), nem por isso é possível falar de sujeito sem mencioná-lo na usurpação de seu lugar de corpo.

Isso posto, vejamos como a pergunta sobre o aspecto subjetivo insubmisso ao significante aparecia no Seminário 3:

Há, com efeito, algo de radicalmente inassimilável ao significante.É, muito simplesmente, a existência singular do sujeito. Por que está ali? Donde ele sai? O que faz ali? Por que vai desaparecer? O significante é incapaz de dar-lhe a resposta, pela boa razão de que ele o coloca justamente além da morte. $O$ significante já o considera como morto, imortaliza-o por essência. (Lacan, 1981, p. 202)

Tudo se passa como se o ponto inicial do processo de escrita do grafo do desejo - aquele no qual começa a linha que, desenhando uma curva retroativa, corta a cadeia significante - viesse, de certa forma, responder a essas interrogações, ou seja, viesse tratar do lugar que deve assumir aquela parte do sujeito que não pode ser recoberta pelo significante. Esse ponto é claramente indicado como a intencionalidade espontânea que nasce da necessidade.

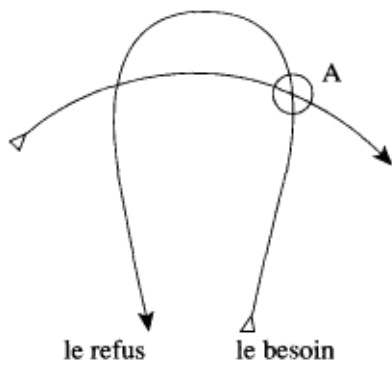

Lacan, 1998, p. 68. Le refus: a recusa; le besoin: a necessidade.

Todo o grafo do desejo nasce do intercâmbio entre o surgimento de uma necessidade e a dialética da recusa que expressa essa necessidade como uma demanda para mostrar, a partir daí, onde tem início o processo de subjetivação. A constituição do sujeito do desejo é o resultado da passagem da demanda pelo Outro, ou seja, a inscrição do significante sobre esse processo que tem origem no corpo pela designação da necessidade como "matéria-prima" do desejo (Lacan, 1986/1998). Lacan assinala expressamente o valor da necessidade:

Se a introdução da demanda comporta alguma perda em relação à necessidade... o que é assim perdido deve ser reencontrado para além da demanda? É claro que, se isso deve ser reencontrado para além da demanda, isto é, do que é trazido de

3 Ver, por exemplo, Lacan (1938). 
distorção à necessidade pela dimensão da demanda, é na medida em que, nesse para-além, devemos encontrar alguma coisa na qual o Outro perde sua prevalência e na qual a necessidade, enquanto algo que parte do sujeito, retoma o primeiro lugar (p. 382, itálicos nossos).

É preciso acrescentar, no entanto, que o lugar da necessidade não existe antes da sua passagem pela fala na formação da demanda. É essa passagem que constitui o lugar da origem da intencionalidade subjetiva retroativamente. Lacan analisa o caso da holófrase, da "frase monólito", na quarta sessão do Seminário 6. Dá os exemplos das interjeições "pão!" e "socorro!"e explica que nelas o sujeito é a sua necessidade que deve surgir na fala: essas frases são "o sujeito enquanto essa necessidade que, sem dúvida, deve passar pelos desfilamentos do significante enquanto necessidade, é expresso de um modo deformado mas ao menos monolítico... e o monólito de que se trata é o sujeito, ele mesmo, nesse nível que o constitui" (Lacan, 1958-1959, p. 80, itálicos nossos). Esse é o primeiro plano da constituição do sujeito.Trata-se da expressão de uma espontaneidade: "o primeiro plano imediato, aparente, espontâneo que éo apelo, (que é"socorro!",que é "pão!",que é um grito no final das contas, que é, em todo caso, algo em que, da forma mais total, o sujeito é idêntico por um momento a essa necessidade)" (Lacan, 1958-1959, p. 129, itálicos nossos). Trata-se, portanto, de algo que se deve a uma atividade pura, porém mítica, do sujeito. $A$ ele deve seguir-se outro, que é o momento do "contar a si mesmo". Nesse caso, o exemplo é o da pequena Anna Freud que, dormindo, enuncia algo como uma lista de objetos desejados: Anna Freud - morangos silvestres - omelete - pudim. Ou ainda o da criança que afirma "Tenho três irmãos: Paulo, Ernesto e eu". Isso significa que a frase de enunciação da necessidade não é, naturalmente, suficiente para dar conta do sujeito, porque nesse plano está ainda faltando o elemento da relação a si, ou seja, o movimento de apresentar a si mesmo como objeto ou alvo da linguagem; noutras palavras ainda, o momento da submissão mais direta do sujeito, por seu nome, à negação do significante. Pela junção dos dois planos, vemos que o caminho da determinação não tem mais o sentido único que partia do significante na direção do sujeito. Ele agora tem como complemento o sentido contrário, que parte da intenção da necessidade na direção do Outro para aí se transformar em outra coisa. No contar a si mesmo, que só surge por ser um contar da necessidade que ele mesmo experimenta, o sujeito, no nível da necessidade que preside à intencionalidade (ou seja, do corpo), certamente se submete ao domínio do significante, conta a si mesmo e diz"eu",desaparecendo em seguida, no momento mesmo dessa enunciação; mas o faz a partir de algo "aquém" do significante, ainda que se trate de um "aquém" cuja existência, findo o processo, não pode mais ser colocada: 
Com a junção [appoint] do significante, um mínimo de transformação - de metáfora, numa palavra - é introduzido nesta [na necessidade], o que faz com que aquilo que é significado seja algo para além da necessidade bruta, seja remodelado pelo uso do significante. Por conseqüência, desde esse começo, o que entra na criação do significado não é uma pura e simples tradução da necessidade, mas uma retomada, reassunção, remodelagem da necessidade, criação de um desejo diferente da necessidade (Lacan, 1998, p. 91).

Então, vemos que é no espaço complicado dessa necessidade sobrepujada - onde o significante entra para, de vez, torná-la inacessível que reside uma parcela mínima de contribuição ativa por parte do sujeito nesse momento da teoria.

Tomemos a representação do ponto de basta, que é o protótipo do grafo do desejo:

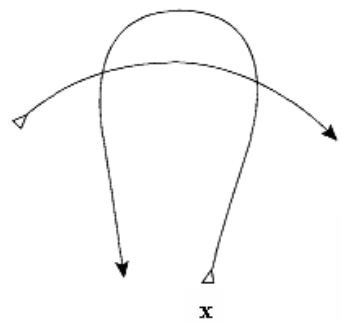

Lacan, 1998, p. 14. A primeira linha, horizontal, é a da cadeia significante; a segunda, que cruza a primeira com um vetor retroativo, é a do discurso racional.

Nessa representação, a intencionalidade subjetiva, localizada no ponto que assinalamos com um " $x$ ", desempenha papel ativo na produção de significação, mesmo que tenha que ser submetida às determinações da cadeia: há um movimento que começa na necessidade subjugada pela demanda, e esse movimento é o que produz o desejo. Contudo, apesar de sua participação, essa intencionalidade não pode ser vista como"a responsável" pela produção do sentido. Lacan se pergunta qual seria o lugar do estofador (leia-se: aquilo ou aquele que é responsabilizado pelo advento da significação) e responde afirmando que tentar situá-lo pontualmente no esquema seria uma atitude ingênua (Lacan, 1998, p. 14), pois, justamente, localizá-lo naquele ponto " $x$ " - ponto onde, no Seminário 6, encontrávamos a intencionalidade subjetiva - corresponderia a reputar toda a operação do sentido ao sujeito. Obviamente, não é o caso. Não se trata de restabelecer um sujeito autônomo - embora Lacan vá fazer referências diretas à autonomia, como veremos adiante -, mas de reconhecer minimamente sua participação. O estofador é irrepresentável na imagem do ponto de basta porque seu lugar aí é simplesmente todo o esquema e não uma parte dele, sujeito ou cadeia significante. Além do 
mais, esse ponto da intencionalidade é o da enunciação da demanda que apenas retroativamente se torna desejo. Então, o sujeito verdadeiro - que é o sujeito do desejo (cf. Lacan, 1961/1966c, p. 656) - sobrepõe-se à demanda sem coincidir totalmente com ela. Não há um sujeito da demanda porque "não há sujeito se não houver um significante que o funde" (Lacan, 1998, p. 189). A existência do sujeito é, ab origine, dividida, porque só encontra representação fora de si, no signo - que não é nem o lugar segundo do outro, mas o lugar terceiro de uma intersubjetividade de outra ordem, o lugar do Outro. Quando a necessidade recebe o estigma do significante, a enunciação da demanda já se tornou desejo. Depois disso, tanto a necessidade quanto a demanda só podem ser vistas como momentos míticos inacessíveis, já que a única forma de abordá-las seria por meio do discurso, na linguagem. Assim, se elas talvez não designem tudo aquilo que, no sujeito, é inapreensível, sem dúvida que respondem por uma grande parcela disso. Vejamos a descrição de sua localização:

Onde está o sujeito? Quando não se trata mais do sujeito ambíguo, ao mesmo tempo perpetuamente inclinado à fala do Outro e capturado na relação especular, dual, com o pequeno outro (a), mas do sujeito constituído, acabado, da fórmula em Z,é o sujeito na medida em que foi introduzida a barra, ou seja, na medida em que ele próprio também está marcado em algum lugar pela relação com o significante. É por isso é que o encontramos aqui, em (\$ <> D), lá onde se produz a relação do sujeito com a demanda como tal (Lacan, 1998, p. 367).

É, então, no plano do vínculo com a demanda que se constitui o sujeito do desejo. E o que é a demanda senão o conluio do corpo com a enunciação? A participação da atividade do sujeito na geração do sentido tem, portanto, que ser circunscrita a esse circuito em que aquilo que existia num primeiro momento (a demanda) só pode ser vislumbrado pela segunda operação (o desejo) exatamente na mesma medida em que nega a primeira, ressignificando-a. A complexidade dessa manobra, que reedita a forma temporal do sujeito, é algo imprescindível para a garantia de que o lugar dessa atividade não seja visto como substância.

Essa análise significa que: se cruzarmos o Seminário 5 com o 6, vemos surgirem modificações na forma como Lacan pensa a produção do sentido, abrindo um lugar um pouco mais evidente para o aspecto ativo da subjetividade - sob a forma da espontaneidade da expressão da necessidade - que havia ficado de fora nos seminários anteriores. Adiante, Lacan (1998) dá continuidade a essa releitura ao comentar que: "o significante existe para servir a alguma coisa - existe para exprimir uma demanda" (p. 86). Ora, é evidente, nesse tipo de declaração, a revisão daquela determinação absoluta cujo único lugar era o funcionamento con- 
junto dos significantes. Há aí, com todas as letras, uma relativização da sua condição: eles existem para servir a algo e não por si mesmos. No entanto, reconhecida essa atividade, ela só pode adquirir, mais uma vez, um caráter paradoxal. $O$ sujeito não é a substância viva, mas desloca-se dela - e, se se desloca dela, é porque tem que pagar alguma espécie de tributo a essa relação.

De todo modo, seria difícil afirmar que o estatuto desse sujeito teria permanecido, em Lacan, impensado ${ }^{4}$. Dobra após dobra, cada passo de seu esforço não parece ter tido outro objetivo a não ser se debater com os detalhes desse problema.Também não parece adequado situá-lo como parti pris metafísico: a noção de sujeito não chega à teoria como escolha filosófica, mas pela consideração de que o fato da fala implica uma posição de desejo que afeta o corpo, modificando-o; não é um princípio, mas um passo inevitável no reconhecimento da estrutura da experiência psicanalítica.

Por outro lado, decerto que o percurso até aqui apresentado não dissolve o conflito determinação $X$ subjetividade. Perdido o momento da necessidade, o sujeito está de volta ao domínio do significante regulando os aspectos singulares da organização do seu desejo. Mas representa, assim mesmo, uma mudança sensível, um avanço significativo, na reconsideração dos princípios assumidos a propósito do estruturalismo ${ }^{5}$. Até porque traz outra conseqüência muito importante, que é a seguinte: a consideração do corpo, por si só, impede que o sujeito seja visto como idêntico ao significante, como Lacan deixa claro: a "ordem simbólica, que o complica [o sujeito], que se superpõe a ele, que não se adere a ele (Lacan, 1998 , p. 461). Sendo constituído pelo simbólico, não se reduz a ele; ao menos por remissão a essa presença ausente da necessidade. $O$ sujeito se identifica - no sentido psicanalítico de "identificação" - como sujeito do significante, mas ele não é o significante e, se não menos se submete aos efeitos da cadeia simbólica, há algo que ele próprio faz entrar nela.

Para continuar a análise desse assunto, desenrolando um outro fio de argumentação que tende a reforçar as conclusões apresentadas até aqui, cabe expor uma hipótese de leitura para algumas teses de $A$ Ciência e a Verdade (Lacan, 1966d). Nesse texto, que é a transcrição da primeira sessão do Seminário 12 - O Objeto da Psicanálise - e a respeito

4 É o que sustenta Van Haute (1992):"Aquilo que inicialmente fora chamado de efeito torna-se agora algo como um princípio subjetivo pressuposto que subjaz a todas as declarações lingüísticas e cujo estatuto, em última instância, permanece impensado. Ademais, este é o'princípio' com o qual a metafísica clássica parece estar comprometida" (p.238).

50 que vai revelar, de forma mais essencial, os motivos do afastamento ou da revisão da referência estruturalista é a análise do tipo de circuito necessário, diante da hipótese do inconsciente, ao ensaio da relação a si na medida em que, surgindo do corpo e não podendo ser reduzido nem à posição do significante nem à do significado, o sujeito continua a se apresentar como negatividade. Essa questão será o alvo de um próximo trabalho. 
do qual não seria demasiado dizer que se trata de uma fala totalmente dedicada a Lévi-Strauss, vemos se sucederem, entre outras, as seguintes afirmações:

1 O estruturalismo foi o que permitiu elaborar logicamente o sujeito entendido como algo constituído por uma divisão (p. 856).

2 Um único sujeito é aceito na psicanálise: aquele que pode conferir-lhe a condição de ciência (p. 859).

3 O estruturalismo introduz "um modo muito especial do sujeito" (p. 861).

4 O índice desse modo é topológico, pois, no estruturalismo - e a referência direta é Lévi-Strauss - "o sujeito está... em uma exclusão interna a seu objeto" (p. 861).

5 A "mitogênese",empreendida por Lévi-Strauss, não se relaciona com o sujeito"mitante" [mythant], mas com o sujeito da ciência (p. 862).

6 Para o sujeito da ciência, a magia e a religião não passam de sombras, mas não para o "sujeito sofredor" com que lida a psicanálise (p. 870).

7 O sujeito que pode garantir condição de ciência à psicanálise é o sujeito submetido ao significante na medida em que este se encontra na posição da verdade como causa material (e não formal, como seria o caso da ciência $\left.{ }^{6}\right)($ p. 875).

8 A originalidade do lugar da psicanálise na ciência é que, no seu caso, a verdade é causa material e não formal (p. 875).

9 O sujeito do significante - o que é veiculado por ele - deve ser profundamente diferenciado do indivíduo biológico e do psicológico (p. 875).

10 O estruturalismo de Lévi-Strauss opera uma redução (como tal, necessária à ciência (p.855)) que negligencia o sujeito pelo seguinte motivo: o sujeito correlato da eficácia simbólica tem que coincidir com o "suporte corpóreo" do xamã. Mas essa coincidência é vedada ao sujeito da ciência posto em causa pelo estruturalismo, porque nele tudo o que é discernível a seu respeito são seus correlatos estruturais (p. 871).

6 Os outros dois casos na complementação dos quatro posicionamentos da causa (pensados a partir de Aristóteles) são a magia e a religião. 
A nosso ver, delas é possível chegar às seguintes conclusões, no que se refere ao escopo do presente estudo:

1 A psicanálise lacaniana toma do estruturalismo a posição da verdade como causa, ou seja, é com o estruturalismo que ela aprende que o tipo de causa aí implicado é causa material, no sentido da materialidade do significante.

2 Mas que, ao contrário do estruturalismo, a psicanálise não pode prescindir da relação do significante com o corpo que, então, é corpo radicalmente repensado em sua distância de subversão para com o corpo biológico.

E aqui devemos conceder atenção especial a uma frase que se refere de modo central ao movimento que tentamos apreender. Lacan diz que "a fidelidade que a obra de Claude Lévi-Strauss manifesta a um tal estruturalismo [esse para o qual a posição do sujeito em relação a seu objeto é de exclusão interna] só será aqui endossada por nossa tese para nos contentarmos momentaneamente com sua periferia" (Lacan, 1966d, p. 861). Para nós, o objeto que Lacan menciona na frase imediatamente anterior não é ainda o objeto a no qual ele se detém duas páginas adiante, mas o objeto tocado pelo estruturalismo, ou seja, o significante. Gostaríamos de solicitar ao leitor que considere a plausibilidade dessa interpretação ao se deparar, então, com essa passagem, agora citada mais amplamente:

Ele [o estruturalismo] introduz, em toda "ciência humana" (entre aspas) que conquista, um modo muito especial do sujeito, aquele para o qual só encontramos índice topológico, digamos: o signo gerador da banda de Moebius, que chamamos de oito interior.

O sujeito está, se assim podemos dizer, em uma exclusão interna a seu objeto.

A fidelidade que a obra de Claude Lévi-Strauss manifesta a tal estruturalismo só será aqui endossada por nossa tese para nos contentarmos momentaneamente com sua periferia (Lacan, 1966d, p. 861).

Lido dessa forma, em seu contexto, o pronome possessivo grifado só pode ter por referente o estruturalismo que se está comentando, e não o sujeito ${ }^{7}$. Não há nada, nem imediatamente antes nem imediatamente depois desse trecho, que permita relacionar o dito pronome possessivo à indicação do objeto $a$. Não há nada também no desenrolar concreto da argumentação que conduza a tal interpretação. Isso significa que, se o estruturalismo (de Lévi-Strauss) é capaz de fornecer um novo tipo de sujeito - e isso só é dedutível pela psicanálise e não pela antropologia - é

7 Para um ponto de vista contrário, ver lannini (2000, p. 81). 
porque ele mostra que a relação desse sujeito com a ordem simbólica é de "exclusão interna"8: ele é logicamente indispensável a seu funcionamento, mas deve ser observada a impossibilidade de sua atualização na linguagem. Ou seja, trata-se de uma frase que retoma toda a reflexão sobre o sujeito desenvolvida no Seminário 11 baseada, através do cogito, na relação entre ser e pensamento, cuja matéria é o significante.

Podemos agora avançar uma leitura precisa do"contentamento momentâneo" que resulta do endosso do estruturalismo. É que, se, por um lado, este fornece a via pertinente da abordagem do sujeito - a qual, ao ser seguida por Lacan, revela sua "obediência científica" (Lacan, 1966d, p. 885) -, por outro, o negligencia - ponto que não pode ser acompanhado pela psicanálise. E essa negligência tem lugar no ponto em que é vedada ao sujeito da ciência a coincidência com o "suporte corpóreo" que, distanciado da biologia, é indispensável à presença da pulsão e à própria estrutura do objeto $a$, tais como requisitadas no ano anterior ao seminário $^{9}$. Resta que à psicanálise cabe a tarefa de pensar a relação do sujeito da ciência, conforme apresentado pelo estruturalismo (ou seja, submetido à verdade como causa material do significante), com a sensibilidade possível e necessária representada pelo corpo.

Após esse percurso, podemos ponderar o sentido da passagem de Lacan por Descartes, pois é ela que nos permite entender o projeto do Seminário 9, na medida em que esse ano de ensino - então consagrado ao tema da identificação através da análise da unidade (do traço) e da negação da igualdade entre " $A$ " e " $A$ " - é um desdobramento direto da forma pela qual o cogito fora trabalhado desde $A$ instância da letra: a distinção dos dois eus (o "eu" do "penso" e o "eu" do "existo") em função de suas posições temporais e gramaticais. Lacan explica nos seguintes termos por que escolheu abrir o ano letivo com a referência a Descartes:

E por que esse ano acreditei dever partir, não do próprio Platão - para não falar dos outros -, mas também não de Kant, não de Hegel, mas de Descartes? Foi justamente para designar que aquilo de que se trata, lá onde reside o problema do inconsciente para nós, é da autonomia do sujeito na medida em que ela não é apenas preservada, mas que ela é acentuada como nunca o foi em nosso campo; e precisamente, em função desse paradoxo, esses encaminhamentos que aí descobrimos não são nunca concebíveis se, falando propriamente, o seu guia não for o sujeito, e isso de forma tanto mais segura na medida em que ele o é sem o saber (Lacan, 1961-1962, p. 68, itálico nosso).

8 Isso nos explica, de certa forma, o fato de Lévi-Strauss falar que o sujeito é categoria dispensável (LéviStrauss, 1971/1991, p. 21). Privilegiaria a face de exclusão, sem poder valer-se do olhar necessário à percepção de sua implicação.

9 Lacan ressaltava esse caráter indispensável também no Seminário 10 ao dizer que:"As referências biológicas, as referências à necessidade são essenciais, é claro; não se trata de as rejeitarmos, mas desde que percebamos que, de fato, a diferença estrutural muito primitiva introduz rupturas nelas, cortes, introduz de imediato a dialética significante" (Lacan, 2004/2005, p. 78). 
Em seguida, explica que a necessidade de destinar um nível de autonomia para o sujeito resulta do fato de ela ser "aquilo pelo qual o sujeito, em nenhum caso, poderia ser reduzido a um sonho do mundo" (Lacan, 1961-1962, p. 69).

A análise de um dos fios do movimento teórico que se estende entre 1957 e 1966 mostra que aquilo que impede a redução do sujeito a um sonho do mundo é a presença do corpo sob a incidência do significante em seus efeitos de alteração do organismo. Para além da imagem corporal e jamais confundido com qualquer espécie de imanência, ele retoma um lugar central na teoria. Não como fato empírico, como se fora um dado previamente dado a ser meramente reconhecido, mas como elemento capturável na estrutura produtora de significância. O corpo é o local originário da inscrição significante que parte do Outro e, portanto, participa das condições lógicas da enunciação. Vemos que Lacan confirma a hipótese logo em seguida, no mesmo seminário. Ao explicitar um pouco mais a tarefa que aí pretende levar a cabo, menciona a oposição entre a "imanência vital" - a ser subvertida sob o modo da pulsão e tornada impossível pelo significante - e o"fato da fala", para então dizer que: "nosso esforço esse ano, se ele tem um sentido, é justamente de mostrar como se articula a função do sujeito não em um ou outro desses pólos, mas jogando entre os dois" (Lacan, 1961-1962, p. 72)

Esse aspecto será, então, enfatizado como fazendo parte daquilo que caracteriza o sujeito tal como implicado pelo significante. Citemos duas passagens que o confirmam diretamente: "Esse mundo subjetivo define-se assim - o significante é, no homem, desde logo entronizado no nível do inconsciente, misturando suas referências com as possibilidades de orientação que seu funcionamento de organismo natural de ser vivo Ihe confere"(Lacan, 1986/1988, p. 91, itálicos nossos); "estamos ligados aos efeitos que resultam da coerência do significante, quando um ser vivo se faz seu agente e suporte" (Lacan, 1991/1992, p. 230, itálicos nossos). Assim, a significação passa a ser definida pela combinação do signo com a vida (Lacan 1961/1966b, p. 594) segundo as modulações da função negativa da linguagem: o nível do vital é negado pelo significante, mas imprescindível para dar conta do fenômeno do sentido, uma vez que este não é dissociável dos caminhos do desejo.

Por outro lado, esse mesmo corpo surgido da usurpação da necessidade pelo significante é também corpo da presença, é o corpo da imagem sujeita ao olhar do outro ou ao olhar do próprio sujeito. É o que vemos, por exemplo, quando Lacan diz que:

O problema está na entrada do significante no real e em ver como disso nasce o sujeito. Será que isso quer dizer que nos encontramos como que diante de uma espécie de espírito que baixa, de aparição de significantes alados? Significa que eles começariam sozinhos a cavar seus furos no real, e que no meio 
apareceria um furo que seria o sujeito? Penso que, quando introduzo a divisão real-imaginário-simbólico, ninguém me atribui tal intenção. Hoje, trata-se de saber o que permite que esse significante se encarne.

O que lhe permite isso é, primeiro, o que temos aí para nos tornar presentes uns para os outros - nosso corpo (2004/2005, p. 100).

Trata-se, aqui, de um outro aspecto do mesmo contexto: a ênfase no corpo, ao lado do surgimento do objeto a (cujos primeiros rudimentos podem ser encontrados justamente no Seminário 6), indica uma recuperação do sensível, cujo destino, ao responder de modo mais pertinente pela condição do sujeito, funciona como ponto de resistência à assimilação significante ${ }^{10}$. De todo modo, o trecho citado indica claramente, mais uma vez, que, se o sujeito entra no simbólico com seu corpo, ainda que ascenda, com isso, a uma realidade que não será jamais imediata e que reservará ao mito a noção de "organismo", há, em todo o processo, lugar para alguma coisa que é ele próprio - o sujeito e não o significante - quem traz à cena. Alguma coisa que é ele próprio que apresenta e que, assim, resguarda para si uma dimensão de efetividade (Wirklichkeit).

Nesses termos, é possível vislumbrar um dos vetores que constrangem a obra de Lacan a uma ultrapassagem decisiva da racionalidade estruturalista. Ao lado de outros vetores - discerníveis sob a necessidade de 1) pensar, sob a forma do Outro, uma estrutura diferenciada, porquanto faltante e não totalizadora e 2) extrair uma configuração da referência a si, que exige o contorno do objeto pela pulsão -, a imposição da consideração da presença corporal já evidencia os rumos pelos quais o sujeito excede a determinação significante.

\title{
Autonomy, Heteronomy: Remark on the Relation Between Body and Structure in Jacques Lacan's Work.
}

\begin{abstract}
The years of 1954 and 1955 correspond to a moment of Lacan's work which can be indicated as the summit of the reference to a structure that, conformed by signifiers, answers for the total determination of the subject. The "subject effect",according to its own definition,comes explicitly to dispense associations with the human being in the sense of what this expression could bear of an indication, whatsoever, of a vital support. With the construction of the graph of desire (1957), the problem begins to receive a new configuration. Since then, we see an insistent retrieval of a role to be assigned to the body in the constitution of desire that arises from the way we think of its relation to necessity and to demand. This paper approaches the terms of this reinsertion and tries to indicate in which sense it begins to circumscribe one of the vectors of the surpassing of the structuralist rationality.
\end{abstract}

Keywords: Psychoanalysis. Structuralism. Body.

10 Sobre essa questão do retorno ao sensível, na medida em que relacionado ao tratamento do objeto, ver os trabalhos de Safatle (2003, p. 211 e 2005). É proposital a indicação de dois anos diferentes? 


\section{Autonomie, Hétéronomie : Remarque sur le Rapport entre Corps et Structure Dans L'oeuvre de Jacques Lacan.}

Résumé: Les années 1954 et 1955 correspondent à un moment de l'oeuvre de Jacques Lacan qui peut être indiqué comme l'apogée du recours le plus direct à la structure, laquelle, conformée par les signifiants, prend en charge la [totale]' détermination du sujet. L'"effet de sujet",à partir de sa propre définition, dispense carrément les associations avec l'être humain en tant qu'un support vital, quel qu'il soit. Dès la construction du graphe du désir (1957) le problème prend une nouvelle configuration: on assiste à une reprise insistante du rôle du corps dans la constitution du désir à partir de la façon dont elle est pensée, de son rapport avec le besoin et la demande. Le présent travail aborde les termes de cette réinsertion faisant ainsi l'indication d'un des vecteurs de dépassement de la rationalité structuraliste.

Mots-clés: Psychanalyse. Structuralisme. Corps.

\section{Autonomía, Heteronomía: Comentario Acerca de la Relación Entre el Cuerpo y la Estructura en la Obra de Jacques Lacan.}

Resumen: Los años de 1954 y 1955 corresponden a un momento de la obra de Jacques Lacan que se puede indicar como el apogeo del recurso más directo a la estructura que, conformada por los significantes, es responsable por la determinación total del sujeto. En ellos, el "efecto de sujeto", a partir de su definición misma, llega a dispensar explícitamente asociaciones con el ser humano en el sentido de lo que podría traer esta expresión de la indicación de cualquier especie de suporte vital. Con la construcción del grafo del deseo (1957), el problema empieza a recibir una nueva configuración. Se atiende, entonces, a una recuperación insistente del papel del cuerpo en la constitución del deseo a partir de la manera en que se piensa su relación con la necesidad y la demanda. El artículo aborda los términos de esa reinserción y busca indicar por qué ella comienza a circunscribir uno de los vectores de la transposición de la racionalidad estructuralista.

Palabras-clave: Psicoanálisis. Estructuralismo. Cuerpo.

\section{Referências}

Iannini, G. (2000). Cartografia de um desencontro. In A. Teixeira \& G. M. Rocha (Orgs.), Dez encontros: psicanálise e filosofia - o futuro de um mal-estar (pp. 73-82). Belo Horizonte: Opera Prima.

Lacan, J. (1938). La famille. In Encyclopédie Française. Vol. 8: La vie mentale (pp. 8'40-3-8'42-8). Paris: Larousse.

Lacan, J.(1958-1959). Le désir et son interprétation - Séminaire 1958 - 1959.Inédito. (Consultado na versão digital da Association Freudienne Internationale)

Lacan, J. (1961-1962). L'identification - Séminaire 1961 - 1962. Inédito. (Consultado na versão digital da Association Freudienne Internationale) 
Lacan, J. (1966a). Le séminaire sur La lettre volée. In Écrits (pp. 11-61). Paris: Éditions du Seuil. (Trabalho original publicado em 1957)

Lacan, J. (1966b). La direction de la cure et les principes de son pouvoir. In Écrits (pp. 585-645). Paris: Éditions du Seuil. (Trabalho original publicado em 1961)

Lacan, J. (1966c). Remarque sur le rapport de Daniel Lagache: Psychanalyse et structure de la personnalité. In Écrits (pp. 647-684). Paris: Éditions du Seuil. (Trabalho original publicado em 1961)

Lacan, J. (1966d). La science et la vérité. In Écrits (pp. 855-877). Paris: Éditions du Seuil.

Lacan, J. (1973). Le Séminaire. Livre 11: Les quatre concepts fondamentaux de la psychanalyse - 1964. Paris: Éditions du Seuil.

Lacan, J. (1978). Le Séminaire. Livre 2: Le moi dans la théorie de Freud et dans la technique de la psychanalyse - 1954-1955. Paris: Éditions du Seuil.

Lacan, J. (1981). Le Séminaire. Livre 3: Les psychoses - 1955-1956. Paris: Éditions du Seuil.

Lacan,J.(1988).OSeminário. Livro 7:A ética da psicanálise - 1959-1960 (A.Quinet, trad.). Rio de Janeiro: Jorge Zahar. (Trabalho original publicado em 1986. Título original: Le séminaire de Jacques Lacan - Livre VII: L'éthique de la psychanalyse -1959-1960)

Lacan, J. (1992). O Seminário. Livro 8: A transferência - 1960-1961. (D. D. Estrada, trad.). Rio de Janeiro: Jorge Zahar. (Trabalho original publicado em 1991. Título original:Le séminaire de Jacques Lacan - Livre VIII:Le transfert - 19601961)

Lacan, J. (1995). O Seminário. Livro 4: A relação de objeto - 1956-1957 (D. D. Estrada, trad.). Rio de Janeiro: Jorge Zahar. (Trabalho original publicado em 1994. Título original: Le séminaire de Jacques Lacan - Livre IV: La relation d'objet - 1956-1957)

Lacan, J.(1998). Le Séminaire. Livre 5:Les formations de l'inconscient - 1957-1958. Paris: Éditions du Seuil.

Lacan, J.(2005). O Seminário. Livro 10: A angústia - 1962-1963 (V. Ribeiro, trad.). Rio de Janeiro: Jorge Zahar. (Trabalho original publicado em 2004. Título original: Le séminaire de Jacques Lacan - Livre X:L'angoisse - 1962-1963)

Lévi-Strauss, C. (1991). O cru e o cozido (B. Perrone-Moisés, trad) São Paulo: Brasiliense. (Trabalho original publicado em 1971. Título original: Le cru et le cuit)

Safatle,V.P. (2003). O ato para além da lei:Kant com Sade como ponto de viragem do pensamento lacaniana. In V.P. Safatle (Org.), Um limite tenso: Lacan entre a filosofia e a psicanálise (pp. 189-232). São Paulo: Editora da UNESP. 
Safatle, V.P. (2005). Uma clínica do sensível: a respeito da relação entre destituição subjetiva e primado do objeto. Interações, 10(19), 123-150.

Van Haute, P. (1992). Lacan's philosophical reference: Heidegger or Kojève? International Philosophical Quarterly, 32(2), 225-238. 